\title{
The estimation of formaldehyde concentration in indoor air
}

\author{
Marina Meshalkina ${ }^{1 *}$, Viktor Sushnikov ${ }^{1}$, and Nadezhda Kryzhova ${ }^{1}$ \\ ${ }^{1}$ Peter the Great St. Petersburg Polytechnic University, Polytechnicheskaya 29, St. Petersburg, 195251, \\ Russian Federation
}

\begin{abstract}
This article is devoted to the measurement of formaldehyde emissions from furniture materials in the classes of St. Petersburg Polytechnic University and kindergartens. An important task of society is to preserve the health of children and students, since they spend a large amount of time in public buildings. The safety of indoor air depends from the materials of which the finishing materials and furniture are made. Formaldehyde is a priority hazardous substance released into the air of confined spaces. Studies were conducted not only for the amount of formaldehyde in the air in the room, but also for the materials from which the furniture was made. Small-sized installation was made for sampling formaldehyde emissions from furniture materials. These emissions were investigated by the photometric method with acetyl acetone reagent. The installation can be used to study the emissions parameters of other components that can be separated from finishing materials and furniture.
\end{abstract}

\section{Introduction}

Health, performance and the existence of humans depend on the quality of air which they breathe their whole lives. $95 \%$ of the time is spent in the closed rooms: at work, home, lounges, recreation and in traffic.

Environmental safety of living residential and industrial buildings becomes more and more important due to a widespread use of poorly investigated chemicals. These chemicals are used to create new constructions and finishing materials.

Air quality is determined by the degree of its contamination by foreign chemicals. These substances are released into the air as an exhaust of manufacturing, transport and other sources. Contaminations then get into living spaces through ventilation system of the buildings.

They mix and react with substances formed during vital activity of human body, work of household devices, release from the various items of furniture, carpets. Hence, air quality inside the buildings can be much worse than outside.

Comparative assessment of air pollutions inside and outside the premises of residential and public buildings showed that its level is usually 2-4 times higher in homes and offices than in the street [1-6].

\footnotetext{
*Corresponding author: meshalkina_mari@mail.ru
} 
More than 100 volatile chemicals - formaldehyde, phenol, benzene, and other nitrogen oxides can be simultaneously present in the atmosphere inside the houses. 500 volatile organic compounds can be in the indoor air. It is basically toxic organic compounds released into the air from synthetic coatings, coverings, wallpaper, carpets, adhesives, mastics, varnishes for furniture and floors. Many toxic components enter in indoor air from working computers.

Solvents are among the major toxic substances released into the indoor air. These are gasoline, kerosene, turpentine, detergents, paint, wax polishes floors and furniture, detergents. These chemical substances are released from the surface and evaporate into the air. Then these substances can be absorbed on various household items. These items are a source of long-term air pollution. Toxic substances accumulate on different surfaces, especially textile. The impact of chemicals on people staying indoors is not only through inhaling. Skin contact with contaminated surfaces can lead to a significant additional damage to a human body. This is an equivalent to inhalation of toxic substances [7-9].

In the articles [10-12] provide data on the study of the action of formaldehyde on the human body at the cellular level.

The concentration of volatile toxic components is highly dependent on ventilation in the indoor environment. The better organized the ventilation, the better the situation with the air quality in the room [13].

Also, the concentration of volatile components increases with increasing temperature $[14,15]$.

\section{Methods}

\subsection{Specific requirements on air quality}

Specific requirements on air quality must be presented to the premises of kindergartens, schools, universities and hospitals. However, the standards and legislation for permissible concentrations inside buildings are not enough developed in Russia.

Therefore we have to refer to maximum permissible concentration (MPC) of pollutants established for open areas.

List of volatile chemicals that must be controlled when assessing the sanitary-chemical state of the air in the room is shown in Table 1.

Table 1. Some Toxic Chemicals.

\begin{tabular}{ll}
\hline Chemical Agent & $\begin{array}{l}\text { Acceptable levels in indoor air, } \\
{\left[\mathrm{mg} / \mathrm{m}^{3}\right]}\end{array}$ \\
\hline Ammonia & 0.04 \\
Butyl Acetate & 0.1 \\
Vinyl Acetate & 0.15 \\
Dibutyl Phthalate & 0.05 \\
Dioctyl Phthalate & 0.05 \\
Methanol & 0.5 \\
Styrene & 0.002 \\
Formaldehyde & 0.035 \\
Phenol & 0.003 \\
Ethyl Acetate & 0.1 \\
\hline
\end{tabular}


Phenol, formaldehyde, ammonia and methanol are the most dangerous to human health. Formaldehyde is determined indoors most often. This substance is used in manufacturing of chipboard and fiberboard, mastics, plasticizers, fillers, lubricants for concrete forms, etc.

Formaldehyde has the formula $\mathrm{CH}_{2} \mathrm{O}$. It is a colorless gas with a pungent, irritating odor, easily polymerized. This substance has the general toxicity, irritate mucous membranes of the respiratory tract, eyes and skin. It has negative effect on genetics, reproductive organs and respiratory tract. Formaldehyde has a strong effect on the central nervous system as well.

Maximum permissible concentration of formaldehyde according to the regulations of Russia in open air: average daily $-0.003 \mathrm{mg} / \mathrm{m}^{3}$, one time maximum $-0.035 \mathrm{mg} / \mathrm{m}^{3}$, in working areas $-0.5 \mathrm{mg} / \mathrm{m}^{3}$. The recommended norms of health officers for indoor air is 0.01 $\mathrm{mg} / \mathrm{m} 3$. Formaldehyde gets into the air from furniture, made from wood chipboard with the addition of formaldehyde resins.

Polymeric materials used for furniture production should be subject to sanitary-chemical evaluation and must meet the following requirements:

- Polymeric materials should not create a specific smell in the ambient air;

- Polymeric materials should not release substances into the room air in quantities that may have direct or indirect adverse effects on the humans.

Materials should be rejected for non-compliance with the above requirements.

\subsection{Organization of the Experiment}

Sanitary-chemical investigations of furniture materials and air quality were carried out in a university laboratory. The main objective of this study was determination of formaldehyde gas emissions.

Special climate chambers with temperature control were used for research. The test sample of furniture was placed in the chamber. Size of the sample was $1 \mathrm{~m}^{2}$ per $1 \mathrm{~m}^{3}$ of a chamber. The edges of the samples not covered with a polymeric material were sealed by aluminum foil with silicone glue.

Samples were kept in the chamber for 3 days at $40^{\circ} \mathrm{C}$. Then the samples were taken out from the chamber and analyzed for formaldehyde content. Chromatographic, infrared and photometric methods were used for measuring formaldehyde content.

Photometric method was the easiest to implement [16-20]. The chromatographic and fluorescence methods of determining formaldehyde in gas form are time consuming and expensive [21-23]. Photometric method with acetyl acetone reagent was implemented in the university. University students were actively involved in the research. Students were able to acquire new knowledge and skills in using equipment for analysis. They also assessed the quality of the environment where the learning process took place.

The small-sized installation was made for sampling formaldehyde emissions from furniture materials. The installation consisted of a thermostatic chamber, sealed desiccator and a Richter absorber was put together for this study. The installation schema is presented in Figure 1. Sanitary-chemical properties of various materials can be investigated with this installation. Pieces of laboratory furniture were used as test materials. 


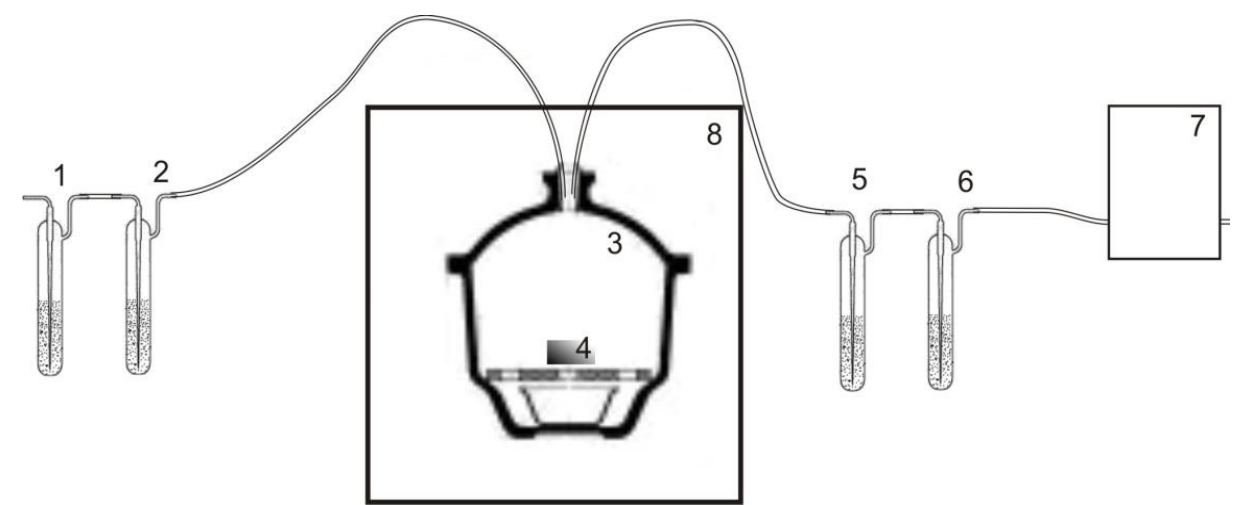

Figure 1. Apparatus for sampling: 1, 2, 5, 6 - Richter absorbers; 3 - desiccator, 4 - sample; 8 thermostatic chamber; 7 - aspirator.

The prepared sample was placed in the thermostatic chamber. Ratio of the sample size to chamber volume was $1 \mathrm{~m}^{2} / 1 \mathrm{~m}^{3}$. The sample was placed in the sealed chamber for 3 days at $40^{\circ} \mathrm{C}$. Air samples were taken using an aspirator and were placed in Richter absorbers. The total volume of the air samples was ten times more than the volume of the chamber.

The non-volatile formaldehyde component was formed during sample preparation. Formaldehyde colors solution in Richter absorbers in yellow. The greater the concentration of formaldehyde, the more saturated was the color of the solution. Simultaneously, control sample was selected from air. The solution from Richter absorber was placed in a cuvette. Measurements of solution absorbance were performed in a spectrophotometer at a wavelength of $412 \mathrm{~nm}$. Formaldehyde concentration was measured using standard sample calibration characteristic.

Formaldehyde concentration was calculated using a ratio of the angle of calibration characteristics. Calibration characteristic was a dependence of absorption from the concentration. Standards had a known concentration of formaldehyde. The absorbance of standard samples was measured with a spectrophotometer. The lower limit of detection of formaldehyde for this method was $0.001 \mathrm{mg} / \mathrm{m}^{3}$.

\section{Results}

The results of measurement of formaldehyde in test samples of furniture materials in a static mode varied from 0.016 to $0.035 \mathrm{mg} / \mathrm{m}^{3}$ in different experiments. Formaldehyde gas emissions did not exceed health standards in tested samples of furniture.

Regular measurements of the concentrations of formaldehyde were conducted in a university laboratory for several months. The laboratory has new furniture. The furniture was made of material samples which were tested before. Density of furniture in this room did not exceed $1 \mathrm{~m}^{2} / 1 \mathrm{~m}^{3}$. Laboratory had volume $168.7 \mathrm{~m}^{3}$, the square of furniture surfaces was $175.6 \mathrm{~m}^{2}$.

Concentration of formaldehyde was minimal and amounted to the value of $0.002 \mathrm{mg} / \mathrm{m}^{3}$ in the empty-ventilated room. The recommended limit of $0.01 \mathrm{mg} / \mathrm{m}^{3}$ was not exceeded. Formaldehyde concentration was highest indoors in hot weather after a long summer vacation and reached the value of $0.043 \mathrm{mg} / \mathrm{m}^{3}$. Concentration of formaldehyde decreased to a safe level in laboratory air after the room was ventilated. Studies in the laboratory were held in a safe and healthy environment.

The authors performed a similar study on the premises of kindergartens in St. Petersburg. These measurements are shown in Table 2.

Table 2. Results of Measurements of Formaldehyde in Kindergartens in St. Petersburg. 


\begin{tabular}{lcl}
\hline Place of Measurement & Concentration of Formaldehyde \\
& {$\left[\mathrm{mg} / \mathrm{m}^{3}\right]$} \\
\hline Kindergarten №29 & 0.008 \\
Kindergarten №32 & 0.004 \\
Kindergarten N26 & 0.008 \\
Kindergarten N20 & 0.009 \\
\hline
\end{tabular}

The formaldehyde contents were much lower in the air of kindergarten rooms than recommended limit. Furniture for kindergartens was bought a long time ago, and the rooms were spacious. Density of furniture in kindergarten rooms was much less than $1 \mathrm{~m}^{2} / 1 \mathrm{~m}^{3}$. Formaldehyde could get into kindergarten rooms from outside air, because they all located in the city center.

\section{Conclusions}

This article shows the results of studies of the safety parameters of furniture materials. The main safety parameter is the emission of toxic substances into the indoor air.

Studies have shown that in all investigated cases the recommended formaldehyde emission limit of $0.01 \mathrm{mg} / \mathrm{m}^{3}$ was not exceeded. The smaller the density of furniture in the room, the less formaldehyde emission is. Formaldehyde gradually disappears from the furniture over time, and its content becomes less.

Should ventilation systems operate properly and density of furniture in the room does not exceed a ratio of $1 \mathrm{~m}^{2}$ of furniture surfaces per $1 \mathrm{~m}^{3}$ volume of the room, the formaldehyde content in the air of such premises is safe for health.

Small-sized compact installation was proposed to conduct research on other building or furniture materials for safety. Sampling of emission of toxic substances from building and furniture materials can be carried out using this installation.

University students assisted in the research. Measurement techniques were used in the educational process.

\section{References}

1. J.C.L. Castro, D.D. Zaborova, T.A. Musorina, I.E. Arkhipov, Mag. Civ. Eng. ,76 (8), 50-57 (2017)

2. H. Järnstrőm, Atmospheric Enviroment, 40, 7178-719 (2006)

3. A.Borodinecs, J. Zemitis, J .Sorokins, D.Baranova, D.Sovetnikov, Mag. Civ. Eng. 68 (8), 58-64 (2016)

4. A.H. Bokowa, Chemical Engineering Transaction 23, 31-36 (2010)

5. I.D. Rae, Environ Chem.5 (1) 1-4 (2008)

6. K.A.Chernyi, G.Z.Fainburg, Mag. Civ. Eng., 54 (2), 6-17 (2015)

7. Review of The Science and Technology of Odor Measurement, St. Croix Sensory Inc McGinlay Associates, 2-8 (2006)

8. C.J. Koecster, A.Moulik, Anal. Chem., 77 (12), 3737-3754 (2005)

9. P. Siekel, Applied Toxicology, 10(5), 239-243 (2006) 
10. A.A. Aizenshtadt, E.B.Burova, V.V. Zenin, D.E. Bobkov, I.V. Kropacheva, G. P. Pinaev, Cell Tissue Biol, 6 (2), 147-153 (2012)

11. A.A. Aizenshtadt, E.B. Burova, V.V. Zenin, D.E. Bobkov, I.V. Kropacheva, G. P. Pinaev, Tsitologiya, 53 (12), 978-985 (2011)

12. E.A. Ivanova, L.N. Erkova, S. Ya. Lazarev, Journal of applied chemistry of the USSR, 59(10), 2189-2193 (1986)

13. I.Yu. Bilous, V.I. Deshko, I.O. Sukhodub Mag. Civ. Eng., 68(8), 65-75 (2016)

14. A.A. Stec, T.R. Hull, K.Lebeck, J.A. Purser, D.A. Purser, Fire and Materials, 32(1), 4960 (2008)

15. D. Baranova, D. Sovetnikov, D. Semashkina, A. Borodinecs, Procedia Eng., 205, 503- 510 (2017)

16. P.R. Chung, C.T. Tzeng, M.T. Ke, Lee C Y, Sensors, 13 (4), 4468-4484 (2013)

17. A. Allouch, M. Guglielmino, P. Bernhardt, C.A. Serra, S.Le Calvé, Sensors and Actuators B: Chemical, 181, 551-558 (2013)

18. R. Wang, A. Prabhakar, R.A. Iglesias, X. Xian, X. Shan, F. Tsow, E.S. Forzani, N. Tao, IEEE Sensors Journal, 12 (5), 1529-1535 (2012)

19. K. Kawamura, K. Kerman, M. Fujihara, N. Nagatani, T. Hashiba, E. Tamiya, Sensors and Actuators, B: Chemical, 105(2), 495-501 (2005)

20. M.N. Descamps, T. Bordy, J.Hue, S. Mariano, G. Nonglaton, E. Schultz, T.H. TranThi, S. Vignoud-Despond, Sensors and Actuators, B: Chemical, 170, 104-108 (2012)

21. A. Gary, J. Gardea-Torresday, E. Overton, A. Carney, Anal.Chem.,76 (12), 3387-3394 (2004)

22. T. Dumas, Journal of Chromatography, 247 (2), 289-295 (1982)

23. G.R. Mohlmann, Applied Spectroscopy, 39 (1), 98-101(1985) 